University of Nebraska - Lincoln

DigitalCommons@University of Nebraska - Lincoln

Faculty Publications from Nebraska Center for Research on Children, Youth, Families, and Schools
Children, Youth, Families \& Schools, Nebraska Center for Research on

2020

\title{
Preventing Teen Relationship Abuse and Sexual Assault through Bystander Training: Intervention Outcomes for School Personnel
}

Katie M. Edwards

Stephanie N. Sessarego

Kimberly J. Mitchell

Hong Chang

Emily A. Waterman

See next page for additional authors

Follow this and additional works at: https://digitalcommons.unl.edu/cyfsfacpub

Part of the Bilingual, Multilingual, and Multicultural Education Commons, Child Psychology Commons, Counseling Psychology Commons, Developmental Psychology Commons, Early Childhood Education Commons, Educational Psychology Commons, Family, Life Course, and Society Commons, and the Other Social and Behavioral Sciences Commons

This Article is brought to you for free and open access by the Children, Youth, Families \& Schools, Nebraska Center for Research on at DigitalCommons@University of Nebraska - Lincoln. It has been accepted for inclusion in Faculty Publications from Nebraska Center for Research on Children, Youth, Families, and Schools by an authorized administrator of DigitalCommons@University of Nebraska - Lincoln. 
Authors

Katie M. Edwards, Stephanie N. Sessarego, Kimberly J. Mitchell, Hong Chang, Emily A. Waterman, and Victoria L. Banyard 


\title{
Preventing Teen Relationship Abuse and Sexual Assault through Bystander Training: Intervention Outcomes for School Personnel
}

\author{
Katie M. Edwards, ${ }^{1}$ Stephanie N. Sessarego, ${ }^{2}$ \\ Kimberly J. Mitchell, ${ }^{3}$ Hong Chang, ${ }^{4}$ \\ Emily A. Waterman, ${ }^{1}$ and Victoria L. Banyard 5 \\ 1 Nebraska Center for Research on Children, Youth, Families, and Schools, \\ University of Nebraska-Lincoln, Lincoln, NE \\ 2 Department of Psychology, University of New Hampshire, Durham, NH \\ 3 Department of Psychology and Crimes against Children Research Center, \\ University of New Hampshire, Durham, NH \\ 4 Tufts Medical Center, Institute for Clinical Research and Health Policy \\ Studies, Boston, MA \\ 5 Department of Social Work, Rutgers University, New Brunswick, NJ \\ Corresponding author: Katie M. Edwards katie.edwards@unl.edu
}

\section{Highlights}

- We examined the impact of a violence prevention program on school personnel outcomes.

- $53 \%$ of participants were exposed to no intervention components.

- Exposure to intervention components led to increases in knowledge.

- Exposure to the student curriculum predicted reactive bystander intentions, and exposure to the handout predicted higher reactive bystander intentions and bystander efficacy.

- Despite challenges with engagement, exposure to the BITB-HSC components may be a useful tool in improving school personnel's responses to RA and SA among high school students.

Published in American Journal of Community Psychology 65 (2020), pp 160-172.

DOI: $10.1002 /$ ajcp.12379

Copyright (C) 2019 Society for Community Research and Action; published by John Wiley \& Sons. Used by permission. 


\begin{abstract}
The purpose of the current study was to examine the impact of exposure to Bringing in the Bystander-High School Curriculum (BITB-HSC) on school personnel, which included a seven session classroom curriculum for ninth through twelfth graders (student curriculum), a bystander training workshop for school personnel (school personnel workshop), and reading materials (handout). We examined how exposure to these various BITB-HSC intervention components was associated with school personnel's knowledge and bystander efficacy, intentions, and barriers specific to student relationship abuse (RA) and sexual assault (SA). Participants were 488 school personnel from 12 high schools in upper New England who completed the 4-month follow-up survey that assessed for intervention exposure (284 participants completed both the baseline and follow-up survey). Whereas $53 \%$ of participants were exposed to no intervention components, the other half of the sample were exposed to a combination of intervention components. Higher baseline knowledge and reactive bystander intentions were associated with subsequent exposure to both the student curriculum and the handout, and fewer barriers to bystander action predicted exposure to the school personnel workshop. Exposure to the school personnel workshop, student curriculum, and handout was associated with subsequent greater knowledge, exposure to the student curriculum predicted reactive bystander intentions, and exposure to the handout predicted higher reactive bystander intentions and bystander efficacy. Findings suggest that despite challenges with engagement, exposure to the BITB-HSC components may be a useful tool in improving school personnel's responses to RA and SA among high school students.
\end{abstract}

Keywords: Bystander, Sexual assault, Sexual harassment, Relationship abuse, Dating violence, School Personnel, Teachers Training, Intervention Prevention

\title{
Introduction
}

Relationship abuse (RA) and sexual assault (SA) are pervasive public health issues among high school teens (Basile, Smith, Breiding, Black, \& Mahendra, 2014; Espelage, Low, Anderson, \& De La Rue, 2014; Vagi, Olsen, Basile, \& Vivolo-Kantor, 2015; Young, Grey, \& Boyd, 2009). For example, in the past 12 months, national data suggest that $6.9 \%$ of high school students were forced to do something sexual by a dating partner, and $8.0 \%$ of high school students were physically hurt on purpose by a dating partner (Kann et al., 2018). Research also suggests that RA and SA are related to a host 
of negative psychological, physical, social, and academic outcomes (Banyard et al., 2017; Edwards, 2015; Exner-Cortens, Eckenrode, \& Rothman, 2013).

Because of the concerning rates and deleterious outcomes associated with RA and SA, there has been an increasing focus on developing and implementing comprehensive strategies to prevent RA and SA among teens. To date, most RA and SA prevention efforts have targeted teens through classroom-based education and training (Edwards, Neal, \& Rodenhizer-St€ampfli, 2017). While classroombased prevention is one component to RA and SA prevention, experts agree that other strategies are needed, including those that target risk and protective factors at outer realms of the social ecological model (DeGue et al., 2012, 2014; Tharp et al., 2013) and initiatives that engage the important adults in the lives of teens (Charmaraman, Jones, Stein, \& Espelage, 2013; Espelage, Low, Polanin, \& Brown, 2013; Yoon \& Barton, 2008; Yoon \& Bauman, 2014).

School personnel, which include school administrators, teachers, coaches, and support staff (e.g., bus drivers), are likely an important group to target as part of comprehensive RA and SA prevention among teens. Indeed, there is research to suggest that prevention programming for youth (across a variety of health behaviors) is most effective when it also engages parents and school personnel (Finkelhor, Vanderminden, Turner, Shattuck, \& Hamby, 2014; Thornton, Craft, Dahlberg, Lynch, \& Baer, 2000; Whitted \& Dupper, 2005). Consistent with a bystander-focused approach to prevention (Banyard, 2015; Banyard, Edwards, \& Seibold, 2015; Banyard, Weber, Grych, \& Hamby, 2016; Edwards, Mattingly, Dixon, \& Banyard, 2014; McMahon, 2015), engaging important adults in the lives of youth is key because these individuals can be taught to model the attitudes (e.g., resistance to violence accepting attitudes) and behaviors (e.g., positive bystander action, and nonviolent behaviors) we are attempting to promote in youth.

Indeed, youth themselves describe how both parents and school staff play roles in facilitating youth bystander action to prevent bullying and RA; for example, youth reported perceptions that parents and school staff would want them to help in situations of bullying (Casey, Lindhorst, \& Storer, 2016). Although research suggests that parents play a key role in socializing their children about intimate relationships (Akers, Yonas, Burke, \& Chang, 2011; Arriaga \& Foshee, 2004; 
George et al., 2013; Wilson, Dalberth, \& Koo, 2010), youth who may be most vulnerable to RA and SA may experience parental absence (Demuth \& Brown, 2004; Fritsch \& Burkhead, 1981) and/or poor parental support (Ghate \& Hazel, 2002; McLoyd \& Wilson, 1991). Thus, other important adults, such as school personnel, may play important roles in shaping adolescent identity formation (Harrell-Levy \& Kerpelman, 2010) and helping promote healthy relationships (Benhorin \& McMahon, 2008; Hymel, McClure, Miller, Shumka, \& Trach, 2015; LaRusso, Romer, \& Selman, 2008). Indeed, school personnel are often the first to notice warning signs of RA and SA due to school personnel's daily interactions with youth and their ability to identify changes in behaviors, academic performance, and peer interactions (Arriaga \& Foshee, 2004; George et al., 2013; Santor, Messervey, \& Kusumakar, 2000).

Moreover, a substantial portion of RA and SA take place on school property and in the presence of witnesses; $40 \%-66 \%$ of RA among teens occurs in the presence of witnesses and 18\%-72\% of SA happens on school property (Black, Tolman, Callahan, Saunders, \& Weisz, 2008; Molidor, Tolman, \& Kober, 2000; Turner, Finkelhor, Hamby, Shattuck, \& Ormrod, 2011; Young et al., 2009). The varying rates of SA and school property are driven by high rates of sexual harassment that occurs on school property, whereas rates of forced sex on school property are lower. Nevertheless, these data suggest that school personnel likely have ample opportunity to serve as positive bystanders in these situations of teen RA and SA. Moreover, in a qualitative study with 22 high school personnel, researchers found that school personnel intervened both during (e.g., breaking up fights between dating partners) and after (e.g., comforting victims) instances of teen RA and SA (Edwards, Rodenhizer, \& Eckstein, 2017). Further, school personnel were more likely to take-action when barriers (e.g., not having the skills to help in situations of student RA and SA) were perceived to be low (Edwards, Rodenhizer, et al., 2017).

In addition to directly intervening during and after situations of RA and SA, Edwards, Rodenhizer, et al. (2017) found that school personnel discussed ways they could proactively take-action (e.g., talking with teens about healthy relationships) even in the absence of RA and SA. This finding is especially promising given that researchers have found that greater demonstrations of gender equity and intolerance of sexual harassment among school personnel were associated with 
lower rates of self-reported SA and sexual harassment victimization and perpetration among middle school students (Espelage, Polanin, \& Low, 2014; Rinehart \& Espelage, 2016). Additionally, other research that has focused specifically on school personnel's reactions to bullying among middle and high school youth has found that (a) school personnel are more likely to provide youth with educational information on bullying than to directly intervene in bullying situations (Novick \& Isaacs, 2010); (b) school personnel who felt prepared to take action in youth bullying situations were more likely to take action in real bullying situations than school personnel who did not feel prepared to do so (Novick \& Isaacs, 2010); and (c) youth are more likely to seek help from teachers who were seen as effective and fair in the action they took to address bullying among teens (Aceves, Hinshaw, MendozaDenton, \& PageGould, 2010).

To date, we are not aware of any evidence-informed workshops for school personnel that seek to prevent teen RA and SA using a bystander-focused framework. Nevertheless, there are a handful of school personnel trainings and workshops targeting a number of health behaviors that have been documented and/or evaluated in the scholarly literature. For example, the GREAT (Guiding Responsibility and Expectations in Adolescents Today and Tomorrow) teacher program is a prevention program for middle school teachers to deter students' aggressive behavior (Miller-Johnson, Sullivan, Simon, \& Multisite Violence Prevention Project, 2004; Orpinas, Home, \& Multisite Violence Prevention Project, 2004). Teachers participated in a 12-hour workshop and 10 support group sessions. Teachers rated their own behavior, in terms of knowledge and application of skills to prevent violence and self-efficacy to facilitate prosocial student behavior. A number of other school-based programs exist aimed at preventing violence and aggression and reducing risk behaviors; these programs often involve training and implementation by school personnel, emphasizing the important role these adults have in the lives of today's youth (Chapman, Buckley, Sheehan, \& Shochet, 2013). Few, however, have tracked and documented the impact of such training and experiences on the school personnel themselves.

In sum, school personnel have a critical role to play in preventing and responding to RA and SA for the purposes of (a) shifting norms among youth to be intolerant of RA and SA and promoting healthy 
dating and sexual relationships among youth; (b) taking action to stop RA and SA if it appears likely to happen or has already begun; (c) assisting victims in the aftermath of an incident of RA or SA and (d) as gatekeepers who can potentially champion or work against the use of new prevention strategies in schools.

The purpose of this study was to examine outcomes of the Bringing in the Bystander-High School Curriculum (BITB-HSC) among school personnel. The BITB-HSC included three potential components to which school personnel could have been exposed: a seven session classroom curriculum for ninth through twelfth graders (student curriculum), a bystander training workshop for school personnel (school personnel workshop), and reading materials (handout).

The BITB-HSC student program is a seven session classroom curriculum was delivered to a mixed sex audience and co-facilitated by male and female-identified young adults (mostly college students; see Edwards, Banyard, et al., 2019, for an overview of the student curriculum). BITB-HSC teaches students how to safely and effectively intervene before, during, and after situations of RA and SA to both prevent and stop these forms of abuse from happening, as well as supporting victims in the aftermath of these experiences. Using a 26-school cluster randomized control trial, researchers conducted an initial efficacy trial of the BITB-HSC program. The results showed that students exposed to the BITB-HSC demonstrated significant short-term changes in rape myths, victim empathy, and bystander barriers, and long-term changes in media literacy, bystander readiness, and knowledge relative to youth in the control conditions (Edwards, Banyard, et al., 2019). Although the BITBHSC had little long-term impact on actual bystander behavior, there were reductions in sexual harassment and stalking among students in the intervention condition compared to the control condition.

The BITB-HSC also includes a 6o-minute workshop (i.e., school personnel workshop) for school personnel that provides them with knowledge about RA and SA and the critical role of bystanders in preventing these forms of aggression. The workshop was developed alongside the student program. The workshop provides school personnel with specific behavioral strategies for how they can talk to teens about RA and SA, model healthy attitudes and behaviors for teens, and intervene safely and effectively in situations of teen RA and SA. In the 
present study, the school personnel workshop was facilitated or cofacilitated at a staff meeting by the lead developers of the BITBHSC and/or the principal investigator (PI) of the grant.

The final and third component of the BITB-HSC is a twopage handout that includes definitions of RA and SA, warning signs of RA and SA, how to help victims of RA and SA, how to intervene with perpetrators of RA and SA, and information about local and national RA and $S A$ resources.

We examined how exposure to these various BITBHSC intervention components impacted school personnel's knowledge and bystander efficacy, intentions, and barriers to intervening in teen situations of RA and SA. Additionally, we examined factors that predicted exposure to the BITB-HSC intervention components as well as school personnel's perceptions (e.g., acceptability) of intervention components. The specific research questions of the current study were as follows:

1. (Research Question 1) To what extent did school personnel in treatment schools report engaging with each of the three different intervention components?

2. (Research Question 2) What demographic, knowledge, and attitudinal factors predict engagement in the intervention components? Demographic variables of interest included age, sex, and race/ethnicity; and attitudinal variables of interest included RA and SA knowledge, bystander intentions, bystander barriers, and bystander efficacy. Given the absence of studies on this topic, these analyses were exploratory and we did not have direct hypotheses.

3. (Research Question 3) Was school personnel's engagement in the intervention components' associated with knowledge, bystander intentions, bystander efficacy, and/or bystander barriers? We generally hypothesized that engaged personnel would show more positive outcomes compared to staff who were not engaged.

4. (Research Question 4) What did school personnel like most and least about each of the intervention components? This was a qualitative exploratory aim of the proposed study, and thus, we had no a priori hypotheses. 


\section{Method}

\section{Design}

These data are embedded in a larger project that evaluated via a cluster randomized control trial the BITB-HSC among high school students during the 2014 to 2015 academic year (see Edwards, Banyard, et al., 2019 for student outcome data). In the larger study, high schools $(N=25)$ were randomly assigned to the treatment $(n=12)$ or control $(n=13)$ condition; in the current paper, we use survey data from school personnel in the treatment condition $(N=488)$ who completed a 4-month follow-up survey (at which time point exposure to intervention components was assessed since the intervention components were delivered between the baseline and 4month follow-up survey). School personnel were recruited by emails sent out by school administrators and fliers placed in the school. Because not all school personnel in the treatment schools completed the intervention components, we were able to compare school personnel over time, all within treatment schools, as a function of exposure to intervention components; thus, we used a nonexperimental, observational design.

School personnel within treatment schools could potentially be exposed to three intervention components: (a) student program; (b) school personnel workshop; and/or (c) handout. Regarding recruitment efforts for the school personnel workshop, in all but one school, the school personnel workshop was held during a regularly scheduled staff meeting so that most of the school's staff would be present. In one of our larger schools in which we were not permitted to attend a regularly scheduled school staff meeting, the workshop was held on a teacher workday, and teachers were invited to attend via email and word of mouth. Although the workshop is intended to be 60 minutes, due to time restraints imposed by school administrators, across the 12 schools, the timing of the workshops ranged from 10 to 60 minutes $($ Mean $=32.23, S D=15.90$; there were no significant differences in outcomes based on length of the workshop). Regarding the modifications, there was a hierarchy of the most to least important information to convey that was used to determine which portions of the program to cut for consistency purposes. This hierarchy was determined by the program developers. The number of attendees ranged 
from approximately 25 to 120 (Mean $=60.42, S D=32.44$ ). Regarding the handout, we requested that the principal of each school email the handout to all school personnel. Whereas all school personnel were invited to attend the school personnel workshop and read the handout, only school personnel, most commonly academic subject teachers, whose students were being exposed to the BITB-HSC were invited to sit in on the BITB-HSC.

\section{Participants}

Participants were 488 high school personnel from 12 high schools in northern New England (i.e., Maine, New Hampshire, Massachusetts) who completed the 4-month follow-up survey (when exposure to the intervention components was assessed). Of the 488 school personnel who did the follow-up survey, 284 did T1 (Time 1; baseline) (58.2\%; see section below on how missing data were handled for independent variables).

The mean age of participants who completed the follow-up ( $N=$ 488 ) was 44.75 (range $=22-78, S D=12.29$ ). The majority of participants identified as female (71.2\%) and White (96.1\%). The sample was comprised of academic subject teachers (56.5\%), academic support staff $(17.1 \%)$, special education teachers $(8.4 \%)$, counselors/social workers (6.8\%), administrative support (3.7\%), physical education teachers and coaches $(2.9 \%)$, administrators $(2.4 \%)$, nurses $(1.1 \%)$, and facility support (1.1\%). On average, school personnel had worked at the school for 9.70 years (Range $=0.17-45.00$ years, $S D=$ 8.38 years). The mean age of participants who completed the baseline $(N=284)$ was 45.21 (Range $=22-78, S D=12.46)$. The majority of participants identified as female $(72.7 \%)$ and White (98.2\%). The sample was comprised of academic subject teachers (58.5\%), academic support staff (13.8\%), special education teachers (3.1\%), counselors/social workers ( $8.1 \%)$, administrative support (2.3\%), physical education teachers and coaches (3.1\%), administrators (2.7\%), nurses $(1.5 \%)$, and facility support (1.2\%). On average, school personnel had worked at the school for 10.10 years (Range $=0.25-37.00$ years, $S D=8.56$ years). We ran a series of $t$-tests and chisquare tests to compare school personnel who did not take the baseline survey ( $n$ $=204)$ to school personnel who took the baseline survey $(n=284)$. 
School personal who took the baseline survey were more likely to be White and less likely to be academic support. Groups did not differ on gender, position except academic support, age, and years worked at the school.

\section{Recruitment and Data Collection}

Following institutional review board approval, a high school administrator sent out an email from the PI describing the study and inviting all school personnel to participate in a series of two surveys. There was a baseline survey and a survey that occurred approximately 4 months after the baseline survey that used the same recruitment procedures. At each survey, the PI also requested that school administrators (a) include a brief statement prior to the PI's recruitment email encouraging school personnel to complete the survey, (b) send a reminder email to school personnel a few weeks after the initial request was sent, and (c) make an announcement about the survey at staff and faculty meetings. Additionally, fliers advertising the study were posted in different areas of the school (e.g., staff lounge, mailroom) where school personnel frequented.

All recruitment messages contained a link to the online survey (which was unique to each school); one individual requested to complete a paper and pencil version of the survey via mail. All participants were provided with a detailed description of the study; informed consent was obtained at each time point, given they may not consistently participate in all surveys, by having participants check a box at the beginning of the online survey indicating they read and understood the consent form and wished to participate.

Fifty-eight percent of the school personnel in our sample completed the T1 survey. Following the completion of the survey, participants were provided with a list of resources to learn more about relationship abuse and sexual assault, as well as information on how to get help personally for these issues. Participants had the opportunity to enter their name into a raffle for the chance to win one of two $\$ 200$ gift cards at each time point, for a total of four $\$ 200$ gift cards. At the end of the survey, participants were redirected to an entirely new survey to enter their name into the gift card raffle so that their survey responses would remain anonymous. 


\section{Measures}

With the exception of the intervention exposure and feedback questions (which were only administered at the follow-up survey), all of the measures described below were administered at the baseline and 4-month follow-up surveys. We re-administered the demographics in order to facilitate matching participant data over time in conjunction with the use of self-generated ID codes.

Demographics

A brief demographic questionnaire was used to assess sex (dichotomous; 1 = male $; 2$ = female), race (dichotomous; $0=$ non-White $; 1$ =White), age (continuous), time worked at the school (continuous), and if the participant has a child under the age of 18 (dichotomous; $1=$ yes; 2 = no).

\section{Knowledge}

We created seven questions to assess school personnel's knowledge about RA and SA. Items on the Knowledge Questionnaire-School Personnel (KQ-SP) were included based on factual information provided as part of the BITB-HSC (Leyva \& Eckstein, 2015). Response options for each of the seven items (e.g., "About half of rape allegations are false") were as follows: 1 (true), 2 (false), and 3 (unsure). Items were then recoded based upon response accuracy, o (inaccurate, including unsure) and 1 (accurate), and summed so that higher scores are indicative of greater knowledge about relationship abuse and sexual assault.

\section{School Personnel Barriers to Bystander Action}

The Barriers to Bystander Action Scale-School Personnel (BBASSP) was created for the purposes of this project, modeled after previous research (Edwards, Rodenhizer, et al., 2017), to assess students' school personnel's perceived barriers to take bystander action in situations of teen RA and SA. Response options on each of the items ranged from 1 (disagree strongly) to 4 (agree strongly). Factor analyses 
suggested that there are two factors or subscales: intervening worsens situation (e.g., "intervening will only make the situation worse") and cannot intervene (e.g., "I do not have the knowledge or skills to intervene") (Edwards, Sessarego, et al.. 2017). Items on each subscale are summed so that higher scores represent higher levels of each barrier. In the current sample, Cronbach's alpha for intervening worsens the situation was 0.57 at Time 1 and 0.67 at Time 2. Cronbach's alpha for cannot intervene was 0.59 at Time 1 and 0.61 at Time 2.

\section{Bystander Intentions}

The Bystander Intent to Help Questionnaire-School Personnel (BIHQ-SP) was based on previous research with high school students and high school personnel (Edwards, Rodenhizer, et al., 2017) and used to capture school personnel's intention to intervene in situations of teen relationship abuse and sexual assault. The BITQ-SP consisted of seven items with response options range from 1 (very unlikely) to 4 (very likely). Factor analyses of the seven items suggested there were two distinct factors or subscales: proactive bystander intentions (e.g., "Talk to teens about getting help for abuse and SA") and reactive bystander intentions (e.g., "Verbally tell a dating couple in a verbal fight to stop”) (Edwards, Sessarego, et al., 2017). In the current sample, Cronbach's alpha for reactive bystander intentions was 0.80 at Time 1 and 0.78 at Time 2 . Cronbach's alpha for proactive bystander intentions was 0.66 at Time 1 and 0.63 at Time 2. Items on each subscale are summed such that higher scores reflect higher levels of intentions to engage in behaviors that may prevent situations of RA and SA and higher levels of intentions to respond to such situations, respectively.

\section{Bystander Efficacy}

Modeled after previous research (Banyard, 2008; Banyard, Moynihan, Cares, \& Warner, 2014), we created 12 statements, comprising the Bystander Efficacy Scale-School Personnel (BES-SP), that assessed school personnel's confidence in their ability to perform various bystander actions in situations of teen RA and SA. On each of the items, participants rate their confidence to perform the behavior on a scale from o (quite uncertain) to 100 (very certain). Factor analyses of the twelve items suggested that there are three separate factors 
or subscales: verbal disagreement (e.g., "Express discomfort if a student says rape victims are to blame for rape"), providing help (e.g., "Get help for a student who tells me they are in an abusive relationship"), and speak out against excuses for assault (e.g., "Speak up to a student making excuses for using physical abuse") (Edwards, Sessarego, et al., 2017). The items of each subscale are summed; higher scores indicate greater agreement with items that comprise the subscale. Cronbach's alphas were as follows: verbal disagreement (Time 1: 0.76; Time 2: 0.72), providing help (Time 1: o.80; Time 2: 0.71), and speak out against excuses for assault (Time 1: 0.71; Time 2: 0.88).

\section{Intervention Exposure and Feedback Questions}

Three questions were created by the research team and administered to school personnel to assess exposure to intervention components (e.g., "Did you receive and read the UNH Bringing in the Bystander fact sheet on relationship abuse and sexual assault?" with response options yes or no). We also asked individuals via open-ended questions what they liked most about each intervention component as well as what they would suggest we change about each intervention component.

\section{Quantitative Data Analysis}

\section{Missing Data Analysis}

Missing data for continuous outcome measures (i.e., knowledge, victim empathy, media literacy) were imputed using what is commonly known as the "prorated scale score." Scales are imputed if half or more of the items have valid, nonmissing responses, but not all of the items within the scale are answered. If a participant had missing responses for at least half of the items, the scale is then set to missing. Scale scores are computed by (a) summing the item scores, (b) dividing the resulting sum by the total number of items within the scale, (c) replacing the missing items with the average score, and, finally, (d) transforming the scale score to a zero to 100 continuum. We had about $1 \%-2 \%$ missing values on demographic variables and, for all other variables, $4 \%-9 \%$.

Analysis Plan 
We conducted three types of analyses to address our research questions. First, the raw frequencies for the sample at the follow-up were calculated to examine the extent to which school personnel in treatment schools were exposed to various BITB-HSC intervention components. For the second research question, we used logistic regressions to predict exposure to each of the three different intervention components (measured at the follow-up) as a function of baseline characteristics, specifically demographic information, knowledge, bystander intentions, bystander efficacy, and bystander barriers. Finally, we conducted a series of linear regression analyses to examine differences in outcomes (measured at the follow-up) as a function of exposure to intervention components adjusting for baseline demographics. All analyses were restricted to those who were in the treatment schools.

\section{Qualitative Data Analysis}

Two graduate-level research assistants, under the supervision of the first author, engaged in content analysis (Neuendorf, 2016) of participants typed responses about what they liked most and least about each of the intervention components. First, coders read the responses to obtain the gestalt of the data. Second, words, phrases, and sentences that answered the questions were highlighted. Third, similarities and differences in the responses to each of the questions were noted and this led to the emergence of categories of similar responses. After coding the responses, we read through them again and compared the responses to our written results to ensure the accuracy of our coding.

\section{Results}

Aim 1: Extent of Exposure to Intervention Components

Over half $(52.8 \% ; n=220)$ of participants in treatment schools were exposed to no intervention components. Nearly one half (43.2\%; $n=180$ ) of school personnel reported that they attended the school personnel workshop, 105 (25.2\%) of school personnel said that they received and read the handout, and 36 (8.6\%) of school personnel 
Table 1 Rates of exposure to various intervention components among school personnel in treatment schools $(N=488)$ at the follow-up

\begin{tabular}{lrr} 
Exposure to: & $\%$ & $N$ \\
\hline No intervention components & 52.8 & 220 \\
Handout only & 2.2 & 9 \\
Workshop only & 18.0 & 75 \\
Student program only & 1.4 & 6 \\
Workshop + handout & 18.5 & 77 \\
Student program + handout & 0.5 & 2 \\
Student program + Workshop & 2.6 & 11 \\
Student program + Workshop + handout & 4.1 & 17
\end{tabular}

Note: 71 participants did not answer at least one of the intervention component questions at the follow-up. Thus, when calculating the exposure rate, the denominator was set to 417 .

reported that they observed the student program for ninth through twelfth graders. See Table 1 for all possible combinations of intervention component exposure among school personnel.

Aim 2: Predictors of Intervention Engagement

As demonstrated in the results presented in Table 2, individuals who had higher levels of knowledge at baseline were more likely, compared to individuals with lower levels of knowledge, to report at the follow-up engagement with the student program and the handout. Similarly, participants higher in reactive bystander intentions, compared to individuals lower in reactive bystander intentions, were more likely to watch the student program and read the handout. There was a marginally significant effect for reactive bystander intentions such that school personnel who had higher levels of reactive bystander intentions were somewhat more likely to report at the follow-up engagement with the school personnel workshop. Finally, there was a significant effect for bystander barriers (intervening makes things worse) such that school personnel who had lower levels of this construct were likely to report at the follow-up engagement with the school personnel workshop. 
Table 2 Predicting school personnel's participation in intervention components using logistic regressions, odds ratios (OR), 95\% confidence intervals (CI), and $p$ values

\begin{tabular}{|c|c|c|c|c|c|c|}
\hline \multirow[b]{2}{*}{ Variable } & \multicolumn{2}{|l|}{$\begin{array}{l}\text { See student } \\
\text { program232 }(27)^{\mathrm{a}}\end{array}$} & \multicolumn{2}{|l|}{$\begin{array}{l}\text { See Personnel } \\
\text { Workshop233(113) }\end{array}$} & \multicolumn{2}{|l|}{$\begin{array}{l}\text { See } \\
\text { handout232 (67) }\end{array}$} \\
\hline & OR $(95 \% \mathrm{CI})$ & $p$ value & OR $(95 \% \mathrm{CI})$ & $p$ value & OR $(95 \% \mathrm{CI})$ & $p$ value \\
\hline Race & $\mathrm{N} / \mathrm{A}^{\mathrm{b}}$ & & $0.93(0.12,7.48)$ & .95 & $\mathrm{~N} / \mathrm{A}$ & \\
\hline Gender & $0.83(0.31,2.21)$ & .71 & $0.72(0.39,1.34)$ & .30 & $0.89(0.44,1.79)$ & .73 \\
\hline Age & $1.01(0.98,1.05)$ & .55 & $0.99(0.96,1.01)$ & .23 & $0.98(0.96,1.01)$ & .14 \\
\hline Child & $0.89(0.36,2.23)$ & .81 & $1.03(0.58,1.84)$ & .92 & $1.44(0.75,2.78)$ & .28 \\
\hline Knowledge & $1.04(1.00,1.09)$ & .03 & $1.01(0.99,1.03)$ & .26 & $1.03(1.01,1.06)$ & .02 \\
\hline \multicolumn{7}{|l|}{ Bystander intentions } \\
\hline Proactive & $1.00(0.97,1.03)$ & .84 & $1.00(0.98,1.01)$ & .62 & $0.99(0.97,1.00)$ & ) .12 \\
\hline Reactive & $1.04(1.01,1.08)$ & .02 & $1.02(1.00,1.04)$ & .05 & $1.03(1.00,1.05)$ & .03 \\
\hline \multicolumn{7}{|l|}{ Bystander efficacy } \\
\hline Verbal disagreement & $0.98(0.94,1.02)$ & .35 & $0.99(0.96,1.01)$ & .31 & $1.02(0.98,1.06)$ & .32 \\
\hline Providing help & $0.98(0.94,1.02)$ & .39 & $1.00(0.97,1.03)$ & .75 & $0.99(0.96,1.03)$ & .73 \\
\hline Speak out against excuses & $1.00(0.96,1.03)$ & .75 & $0.99(0.97,1.01)$ & .43 & $0.98(0.96,1.01)$ & .14 \\
\hline \multicolumn{7}{|l|}{ Barriers to bystander action } \\
\hline Intervening worsens situation & $0.99(0.97,1.02)$ & .46 & $0.99(0.97,1.00)$ & .04 & $0.99(0.97,1.01)$ & .17 \\
\hline Cannot intervene & $1.00(0.96,1.03)$ & .83 & $1.01(0.98,1.03)$ & .66 & $1.00(0.98,1.03)$ & .78 \\
\hline
\end{tabular}

Note: Significant findings are bolded. Marginally significant findings are bolded and italicized. Odds ratios are significant if the confidence interval does not include one. However, due to rounding to hundredth decimal, some significant odds ratios do appear to include one.

a. Reflects the sample size at baseline with $N$ s for those who were exposed to the intervention in the parentheses.

b. Due to small and unreliable cell sizes, comparisons by race for seeing the student program and the handout could not be computed.

Aim 3: Differences in Outcomes as a Function of Intervention Exposure

Results, which are displayed in Table 3, showed that after controlling for demographic variables, school personnel who reported exposure to the student program, school personnel workshop, and handout subsequently had higher knowledge than school personnel without exposure to these intervention components. Furthermore, exposure to the student program and the handout were associated with subsequent higher reactive bystander intentions, and exposure to the handout was associated with subsequent higher bystander efficacy (verbal disagreement). There was a marginally significant effect for bystander barriers (intervening makes things worse) such that individuals who attended the school personnel workshop were marginally lower in this specific type of barrier following the program. Interestingly, individuals who attended the student program were subsequently higher in 
Table 3 Differences in outcomes as a function of exposure to intervention components, regression coefficients, and $p$ values

\begin{tabular}{|c|c|c|c|c|c|c|}
\hline & \multicolumn{6}{|c|}{ Intervention component } \\
\hline & \multicolumn{2}{|c|}{ Saw student program } & \multicolumn{2}{|c|}{ Saw Personnel Workshop } & \multicolumn{2}{|l|}{ Saw handout } \\
\hline & $B(95 \% \mathrm{CI})$ & value & $B(95 \% \mathrm{CI})$ & alue & $B(95 \% \mathrm{CI})$ & $p$ value \\
\hline$N$ & $417(36)^{\mathrm{a}}$ & & $419(181)$ & & $417(105)$ & \\
\hline Knowledge & $6.20^{b}(0.97,11.43)$ & ) .02 & $3.75(0.85,6.64)$ & .01 & $3.80(0.44,7.17)$ & .03 \\
\hline \multicolumn{7}{|l|}{ Bystander intentions } \\
\hline Proactive & $3.40(-2.84,9.63)$ & .29 & $1.90(-1.55,5.35)$ & .28 & $0.07(-3.94,4.08)$ & .97 \\
\hline Reactive & $6.65(0.51,12.80)$ & .03 & $1.15(-2.27,4.57)$ & .51 & $4.24(0.29,8.19)$ & .04 \\
\hline \multicolumn{7}{|l|}{ Bystander efficacy } \\
\hline Verbal disagreement & $2.18(-2.37,6.73)$ & .35 & $0.88(-1.61,3.37)$ & .49 & $2.91(0.05,5.78)$ & .05 \\
\hline Providing help & $1.16(-2.22,4.55)$ & .50 & $0.32(-1.53,2.17)$ & .73 & $1,65(-0.48,3.78)$ & .13 \\
\hline Speak out against excuses & $-1.10(-6.69,4.50)$ & .70 & $-0.18(-3.24,2.87)$ & .91 & $2.29(-1.24,5.82)$ & .20 \\
\hline \multicolumn{7}{|l|}{ Barriers to bystander action } \\
\hline Intervention makes things worse & $7.14(-1.22,15.51)$ & .09 & $-3.93(-8.51,0.66)$ & .09 & $-2.19(-7.50,3.12)$ & .42 \\
\hline Cannot intervene & $1.36(-4.89,7.62)$ & .67 & $0.06(-3.37,3.48)$ & .97 & $-1.78(-5.74,2.17)$ & .38 \\
\hline
\end{tabular}

Note: Significant findings are bolded. Marginally significant findings are bolded and italicized.

a. Reflects the sample size at the first follow-up with Ns for those who were exposed to the intervention in the parentheses.

b. The coefficient reflects the difference in outcome scores at the follow-up between those who reported the participation of the intervention program versus who those reported nonparticipation of the program. The results were adjusted by baseline race, gender, age, and whether one has from the linear regressions. Each outcome variable was measured on the $0-100$.

bystander barriers (intervening makes things worse) than individuals who did not attend the student program.

Aim 4: Qualitative Feedback on Intervention Components

Regarding the workshop, participants gave the following reasons for what they liked most about it: important topic, found it empowering, the delivery of the presentation and/or the facilitators, that it was informative, and/or that they liked the content. Things that participants would like to see changed about the workshop included: the length of it (some said it was too short, whereas others said it was too long), making it less repetitive, having it be more personally relevant, and/ or having it be more interactive/engaging.

In terms of what participants liked most about the handout, individuals remarked that it was concise and clear, informative; that they liked the statistics provided; and that resources included were acceptable. Regarding suggestions for how to improve the handout, 
participants stated that they would like to see more visuals, resources, schools-specific information, and statistics included; some individuals, however, remarked that less information and statistics would be ideal.

Finally, regarding the student program, participants stated that they liked the following components of the program: education, awareness, discussion, case examples, and the presenters. In terms of what they liked least about Table 1 Rates of exposure to various intervention components among school personnel in treatment schools $(N=488)$ at the follow-up the student program, participants mentioned something about the presenters, the time at which the programming was scheduled, and the desire for the program to be more interactive and have more role-plays.

\section{Discussion}

The primary goal of this study was to examine the range and impact of school personnel exposure to companion RA and SA materials (i.e., school personnel workshop, handout) concurrent to a student-focused classroom curriculum (i.e., student program). Whereas $53 \%$ of participants were exposed to no intervention components, the other half of the sample were exposed to a combination of intervention components. Higher baseline knowledge and reactive bystander intentions were associated with subsequent exposure to both the student curriculum and the handout, and fewer barriers to bystander action predicted exposure to the school personnel workshop.

Exposure to the school personnel workshop, student curriculum, and handout was associated with subsequent greater knowledge, exposure to the student curriculum predicted reactive bystander intentions, and exposure to the handout predicted higher reactive bystander intentions and bystander efficacy.

Findings indicated that half the sample of school personnel did not connect with any of the prevention materials. The current research did not enable us to clearly understand why school personnel did not engage. Did they not have time? Did they not see the issue as relevant to their work or their students? A key construct in implementation science is feasibility. While the current study did collect data on school personnel perceptions of the prevention materials, this was only collected from staff who engaged with these materials. Another aspect of 
feasibility would be to do more follow-up with those who did not connect with school personnel focused prevention opportunities.

Interestingly, school personnel who did engage seemed to start the study with what we might consider a higher level of readiness for prevention (e.g., greater knowledge, confidence, previous prevention behaviors). This is consistent with previous work on moderating effects of prevention training on students. For example, Moynihan et al. (2015) found moderating effects of readiness attitudes (including level of denial of the problem and sense of responsibility) on the effects of a bystander training program to prevent sexual violence among college students. This is an important line of inquiry for future research, that is, to better understand who is most likely to engage with prevention. It may be that school personnel who do not already have a foundational level of knowledge about RA and SA do not see the value of prevention materials. This suggests that training materials for staff may need to be varied to better appeal to different levels of readiness to engage with prevention (Banyard, Eckstein, \& Moynihan, 2009). Some school staff may need to start with materials that make a better and more clear foundational case for why prevention is relevant and how prevention can support their specific work. This knowledge may then spur them to engage in the next level of prevention materials that promote skills such as bystander intervention in student situations of RA and SA. Schools should ensure that prevention training is branded in a way that it helps school personnel make clear connections to why this material and training will enhance their own work, the well-being of students, and facilitate the mission of the school.

In terms of the impact of exposure to prevention training materials, knowledge was subsequently higher among school personnel who were exposed to the student program, the Personnel Workshop, and the handout. This makes sense given that factual information about RA and SA was included in all of the intervention components. Moreover, exposure to the student program and handout was associated with higher subsequent levels of reactive bystander intentions; this finding is likely due to the fact that both of these intervention components include a discussion on ways for individuals to safely and effectively intervene in student situations of RA and SA. In addition, despite the brevity of the handout, it appears that the information contained in it was sufficient to demonstrate associations with greater reactive bystander intentions as well as bystander efficacy. The handout 
included specific examples of what to do and what to say to victims and perpetrators of RA and SA, which even without the opportunity to practice skills could explain the higher levels of bystander efficacy among exposed school personnel compared to unexposed personnel. This is encouraging given that school personnel have many competing demands on their time. They are unlikely to have space in their schedules for long trainings. Providing useful and impactful prevention education in short doses may be an effective way to incorporate this often-neglected aspect of school-based prevention. Schools who desire to train staff alongside students should explore the use of engaging handouts like those used in the current study.

It is a bit surprising that exposure of the school personnel workshop was not associated with increases in reactive bystander intentions or bystander efficacy. Nevertheless, this is likely explained by a number of factors including that the classroom program was longer in duration, and thus, teachers watching those sessions were exposed to a greater dose of information and material. Indeed, due to time constraints, the staff-specific workshop was offered for time frames ranging from 10 minutes to an hour. Thus, most school personnel members in the school personnel workshop did not receive a large dose of prevention information or skills on how to effectively intervene in student situations of RA and SA. Moreover, whereas the school personnel workshop was directly targeting school personnel, the other two intervention components were more passive, which could have resulted in school personnel being more receptive to prevention messages delivered via the student program and handout. However, the qualitative findings suggested that some school personnel wished that there was more opportunity in the school personnel workshop to practice intervention skills. Again, using the readiness to change model (Edwards, Jumper-Thurman, Plested, Oetting, \& Swanson, 2000), it may be that school personnel may be best engaged using a more layered approach that begins with a passive handout that does not demand much time from them. This handout can help them see the value of this topic to their work and may motivate them then to pursue follow-up opportunities that using principles of active learning and engage them in skill building.

There was a marginally significant finding for bystander barriers, such that exposure to the school personnel workshop was associated with subsequently lower perceptions that intervening makes things 
worse. The school personnel workshop provided information on how to intervene with both victims and perpetrators and provided specific things to say and do, which could have led to believing that helping in these situations would lead to outcomes that are more positive. Also, hearing other school personnel share success stories of positive bystander action in situations of RA and SA, which happened as part of the school personnel workshop, could have led to reductions in perceived barriers to intervening. We know from previous work with college students that bystanders' feelings about their actions are important to their intent to help in the future (Moschella \& Banyard, 2018). All of these explanations should be interpreted with caution given the nonexperimental design of the study and marginally significant associations.

Unexpectedly, exposure to the student program was associated with marginally higher levels of bystander barriers (intervening makes things worse). There could be a few reasons for this finding, although again caution should be used when considering these interpretations. First, the student program spent ample time having students reflect on their own barriers to positive bystander action. Exposed school personnel could have spent time engaging in the same activities, which may have made them more aware of their barriers to intervening. Indeed, the way in which the questions were worded was more reflect of awareness of barriers as opposed to inaction due to barriers. An alternative explanation for this finding, although speculative, is that during the student program, students discussed myriad situations in which RA and SA occur. These discussions could have led to new awareness in school personnel regarding the various situations of teen RA and SA, which, if unprepared to help in such situations, could have increased perceptions of barriers. Indeed, staff training was not part of the student program and so staff, as passive observers, may have developed more awareness without skill development for addressing what they are now more aware of. Schools who are implementing training for students should make it a priority to also include training for school personnel.

Finally, none of the intervention components were related to proactive bystander behaviors. Across intervention components, there was more of a focus on reactive bystander behaviors compared to proactive bystander behaviors, which could explain this finding. Thus, it will be important for future iterations of this curriculum and/or 
other bystander-focused programming targeting school personnel to include information and skill-building for both reactive and proactive bystander actions.

The lack of engagement in prevention materials by half of the staff points to the need to find new and varied ways to get prevention information into the hands of teachers and other staff. Given that research demonstrates that teachers and school personnel, such as coaches, have a role to play in prevention and that school-based prevention can impact school personnel (Domitrovich et al., 2016), identifying the most effective ways to reach school personnel is critical. For example, one recent study showed that teacher engagement levels in training workshops predicted improvements in teacher participants' levels of effectiveness for addressing bullying (Schultes, Stefanek, van de Schoot, Strohmeier, \& Spiel, 2014). In the current study, we relied on schools to provide time for the school personnel workshop during regular school personnel meetings. However, given the busy agendas of these meetings, it may not be possible to provide detailed skillsbased trainings to school personnel.

Compared to the student programming, the school personnel workshop was quite short, between 10 and 60 minutes. Dosage is a key feature of successful intervention (Nation et al., 2003). Thus, it may be more effective to integrate longer workshop formats that more mirror the classroom curricula, which was found to be effective in impacting a number of outcomes [authors masked for review]. It will be important for school administrators to determine creative ways to make these longer types of trainings feasible, perhaps by offering continuing education credits to school personnel. Further, a lunch and learn format might also be a space and time when staff are better able to engage with materials. New technologies that provide information via apps on a mobile phone could also be considered. For example, a recent review discusses the importance of online communities as a source of professional development for teachers (Maciá \& Garcìa, 2016).

There are several limitations and associated recommendations for future research. First, we were not able to randomly assign school staff to different prevention material conditions. Rather school personnel self-selected into the intervention components, which is a notable limitation of our study. We also had a relatively brief followup period. Thus, future research should utilize random assignment 
and longer follow-up periods. Some of the measures also had less than ideal internal consistency, which is a limitation. Generalizability of findings requires further research with more diverse samples, including more geographic diversity of schools and larger samples of different types of school personnel to better understand differences among school personnel in their prevention engagement. We also did not ask participants their reasons for not engaging with the various intervention components, which would have provided critical information about barriers to school personnel engagement in prevention. We also had limited process evaluation data, such as fidelity, acceptability, and feasibility about the school personnel workshop, which is an important next step for future research.

Nonetheless, despite all of these limitations, the current study represents an important exploration of school personnel engagement with school-based violence prevention programming in a naturalistic setting. We hope that this initial study serves as the foundation for future projects that seek to create violence prevention initiatives that extend beyond exclusively engaging youth and rather focus on engaging the important adults in the lives of youth.

Acknowledgments - We owe a great deal of gratitude to our school and community partners and research assistants and program facilitators. Without these agencies and individuals, this project would not have been possible. Funding for this study was provided by the Centers for Disease Control and Prevention (CDC), Grant \#R01CEO02524. The findings and implications presented in this paper do not represent the official views of the $\mathrm{CDC}$.

\section{References}

Aceves, M. J., Hinshaw, S. P., Mendoza-Denton, R., \& Page-Gould, E. (2010). Seek help from teachers or fight back? Student perceptions of teachers' actions during conflicts and responses to peer victimization. Journal of Youth and Adolescence, 39, 658-669.

Akers, A. Y., Yonas, M., Burke, J. G., \& Chang, J. C. (2011). "Do you want somebody treating your sister like that?”: Qualitative exploration of how African American families discuss and promote healthy teen dating relationships. Journal of Interpersonal Violence, 26, 2165-2185.

Arriaga, X. B., \& Foshee, V. A. (2004). Adolescent dating violence: Do adolescents follow in their friends', or their parents', footsteps? Journal of Interpersonal Violence, 19, 162-184. 
Banyard, V. L. (2008). Measurement and correlates of prosocial bystander behavior: The case of interpersonal violence. Violence and Victims, 23, 83-97.

Banyard, V. L. (2015). Bystander action coils: Moving beyond the situational model. In V. L. Banyard (Ed.), Toward the next generation of bystander prevention of sexual and relationship violence: Action coils to engage communities (pp. 53-75). New York: Springer International Publishing.

Banyard, V. L., Demers, J. M., Cohn, E. S., Edwards, K. M.,

Moynihan, M. M., Walsh, W. A., \& Ward, S. K. (2017). Academic correlates of unwanted sexual contact, intercourse, stalking, and intimate partner violence: An understudied but important consequence for college students. Journal of Interpersonal Violence. https://doi.org/10.1037/couoooo102.

Banyard, V. L., Eckstein, R. P., \& Moynihan, M. M. (2009). Sexual violence prevention: The role of stages of change. Journal of Interpersonal Violence, 25, 111-135.

Banyard, V. L., Edwards, K. M., \& Seibold, W. (2015). Involving community in sexual violence prevention: Engaging bystanders. In R. P. Sturmey (Ed.), Handbook of violence and aggression: Societal interventions (vol. 3). Malden, MA: John Wiley \& Sons.

Banyard, V. L., Moynihan, M. M., Cares, A., \& Warner, R. (2014). How do we know if it works? Measuring outcomes in bystander-focused violence prevention on campuses. Psychology of Violence, 4, 101-115.

Banyard, V. L., Weber, M. C., Grych, J., \& Hamby, S. (2016). Where are the helpful bystanders? Ecological niche and victims' perceptions of bystander intervention. Journal of Community Psychology, 44, 214-231.

Basile, K. C., Smith, S. G., Breiding, M. J., Black, M. C., \& Mahendra, R. (2014). Sexual violence surveillance: Uniform definitions and recommended data elements, version 2.o. Atlanta, GA: National Center for Injury Prevention and Control, Centers for Disease Control and Prevention.

Benhorin, S., \& McMahon, S. D. (2008). Exposure to violence and aggression: Protective roles of social support among urban African American youth. Journal of Community Psychology, 36, 723-743.

Black, B. M., Tolman, R. M., Callahan, M., Saunders, D. G., \& Weisz, A. N. (2008). When will adolescents tell someone about dating violence victimization? Violence Against Women, 14, 741-758.

Casey, E. A., Lindhorst, T. P., \& Storer, H. L. (2016). The situational-cognitive model of adolescent bystander behavior: Modeling bystander decision-making in the context of bullying and teen dating violence. Psychology of Violence, 7 , 33-44.

Chapman, R. L., Buckley, L., Sheehan, M., \& Shochet, I. (2013). School-based programs for increasing connectedness and reducing risk behavior: A systematic review. Educational Psychology Review, 25, 95-114.

Charmaraman, L., Jones, A. E., Stein, N., \& Espelage, D. L. (2013). Is it bullying or sexual harassment? Knowledge, attitudes, and professional development experiences of middle school staff. Journal of School Health, 83, 438-444. 
DeGue, S., Holt, M. K., Massetti, G. M., Matjasko, J. L., Tharp, A. T., \& Valle, L. A. (2012). Looking ahead toward communitylevel strategies to prevent sexual violence. Journal of Women's Health, 21, 1-3.

DeGue, S., Valle, L. A., Holt, M. K., Massetti, G. M., Matjasko, J. L., \& Tharp, A. T. (2014). A systematic review of primary prevention strategies for sexual violence perpetration. Aggression and Violent Behavior, 19, 346-362.

Demuth, S., \& Brown, S. L. (2004). Family structure, family processes, and adolescent delinquency: The significance of parental absence versus parental gender. Journal of Research in Crime and Delinquency, 41, 58-81.

Domitrovich, C. E., Bradshaw, C. P., Berg, J. K., Pas, E. T., Becker,

K. D., Musci, R., ... \& Ialongo, N. (2016). How do schoolbased prevention programs impact teachers? Findings from a randomized trial of an integrated classroom management and social-emotional program. Prevention Science, 17, 325-337.

Edwards, K. M. (2015). Incidence and outcomes of dating violence victimization among high school youth: The role of gender and sexual orientation. Journal of Interpersonal Violence, 33, 1472- 1490.

Edwards, K. M., Banyard, V. L., Sessarego, S. N., Stanley, L. R., Mitchell, K. J., Eckstein, R. P., ... \& Leyva, C. P. (2017). Measurement tools to assess relationship abuse and sexual assault prevention program effectiveness among youth. Psychology of Violence, 8, 537-545.

Edwards, K. M., Banyard, V. L., Sessarego, S. N., Waterman, E. A., Mitchell, K. J., \& Chang, H. (2019). Evaluation of a bystanderfocused interpersonal violence prevention program with high school students. Prevention Science, 2O, 488-498.

Edwards, R. W., Jumper-Thurman, P., Plested, B. A., Oetting, E. R., \& Swanson, L. (2000). Community readiness: Research to practice. Journal of Community Psychology, 28, 291-307.

Edwards, K. M., Mattingly, M. J., Dixon, K. J., \& Banyard, V. L. (2014). Community matters: Intimate partner violence among rural young adults. American Journal of Community Psychology, 53, 198-207.

Edwards, K. M., Neal, A. M., \& Rodenhizer-St€ampfli, K. A. (2017). Domestic violence prevention. In B. T. Bradley \& M. S. Bradley (Eds.), Preventing crime and violence (pp. 215-227). New York: Springer Press.

Edwards, K. M., Rodenhizer, K. A., \& Eckstein, R. P. (2017). School personnel's bystander action in situations of dating violence, sexual violence, and sexual harassment among high school teens: A qualitative analysis. Journal of Interpersonal Violence. https://doi.org/10.1177/0886260517698821.

Edwards, K. M., Sessarego, S. N., Stanley, L. R., Mitchell, K. J., Eckstein, R. P., Rodenhizer, K. A. E., .. . \& Banyard, V. L. (2017). Development and psychometrics of instruments to assess school personnel's bystander action in situations of teen relationship abuse and sexual assault. Journal of Interpersonal Violence, https://doi.org/10.1177/0886260517746946.

Espelage, D. L., Low, S. K., Anderson, C., \& De La Rue, L. (2014). Bullying, sexual, and dating violence trajectories from early to late adolescence. National Institute of Justice. Available from: https://www.ncjrs.gov/pdffiles1/nij/ grants/246830.pdf [last accessed August 16 2019]. 
Espelage, D. L., Low, S. K., Polanin, J. R., \& Brown, E. C. (2013). The impact of a middle school program to reduce aggression, victimization, and sexual violence. Journal of Adolescent Health, 53, 180-186.

Espelage, D. L., Polanin, J. R., \& Low, S. K. (2014). Teacher and staff perceptions of school environment as predictors of student aggression, victimization, and willingness to intervene in bullying situations. School Psychology Quarterly, 29, 287-305.

Exner-Cortens, D., Eckenrode, J., \& Rothman, E. F. (2013). Longitudinal associations between teen dating violence victimization and adverse health outcomes. Pediatrics, 131, 71-78.

Finkelhor, D., Vanderminden, J., Turner, H., Shattuck, A., \& Hamby, S. L. (2014). Youth exposure to violence prevention programs in a national sample. Child Abuse \& Neglect, 38, 677-686.

Fritsch, T. A., \& Burkhead, J. D. (1981). Behavioral reactions of children to parental absence due to imprisonment. Family Relations, 30, 83-88.

George, A. E., Abatemarco, D. J., Terry, M. A., Yonas, M., Butler, J., \& Akers, A. Y. (2013). A qualitative exploration of the role of social networks in educating urban African American adolescents about sex. Ethnicity \& Health, 18, 168-189.

Ghate, D., \& Hazel, N. (2002). Parenting in poor environments: Stress, support and coping. New York: Jessica Kingsley Publishers.

Harrell-Levy, M. K., \& Kerpelman, J. L. (2010). Identity process and transformative pedagogy: Teachers as agents of identity formation. Identity: An International Journal of Theory and Research, 10, 76-91.

Hymel, S., McClure, R., Miller, M., Shumka, E., \& Trach, J. (2015). Addressing school bullying: Insights from theories of group processes. Journal of Applied Developmental Psychology, 37, 16-24.

Kann, L., McManus, T., Harris, W. A., Shanklin, S. L., Flint, K. H., Queen, B., .. . \& Thornton, J. (2018). Youth risk behavior surveillance-United States, 2017. MMWR Surveillance Summaries, 67, 1.

LaRusso, M. D., Romer, D., \& Selman, R. L. (2008). Teachers as builders of respectful school climates: Implications for adolescent drug use norms and depressive symptoms in high school. Journal of Youth and Adolescence, 37, 386.

Leyva, C. P., \& Eckstein, R. (2015). Bringing in the Bystander High school curriculum school personnel workshop. Durham, NH: University of New Hampshire.

Maciá, M., \& Garcìa, I. (2016). Informal online communities and networks as a source of teacher professional development: A review. Teaching and Teacher Education, 55, 291-307.

McLoyd, V. C., \& Wilson, L. (1991). The strain of living poor: Parenting, social support, and child mental health. Children in Poverty: Child Development and Public Policy, 105-135.

McMahon, S. (2015). Call for research on bystander intervention to prevent sexual violence: The role of campus environments. American Journal of Community Psychology, 55, 472-489. 
Miller-Johnson, S., Sullivan, T. N., Simon, T. R., \& Multisite Violence Prevention Project (2004). Evaluating the impact of interventions in the Multisite Violence Prevention Study: Samples, procedures, and measures. American Journal of Preventive Medicine, 26(1 Suppl), 48-61.

Molidor, C., Tolman, R., \& Kober, J. (2000). Gender and contextual factors in adolescent dating violence. Prevention Research, 7, 1-4. Moschella, E. A., \& Banyard, V. L. (2018). Action and reaction: The impact of consequences of intervening in situations of interpersonal violence. Journal of Interpersonal Violence, o886260518782983. https://doi.org/10.1177/0886260518782983

Moynihan, M. M., Banyard, V. L., Cares, A. C., Potter, S. J., Williams, L. M., \& Stapleton, J. G. (2015). Encouraging responses in sexual and relationship violence prevention: What program effects remain one year later? Journal of Interpersonal Violence, 30, 110-132.

Nation, M., Crusto, C., Wandersman, A., Kumpfer, K. L., Seybolt, D., MorrisseyKane, E., \& Davino, K. (2003). What works in prevention: Principles of effective prevention programs. American Psychologist, 58, 449-456.

Neuendorf, K. A. (2016). The content analysis guidebook. Thousand Oaks, CA: SAGE Publications Inc.

Novick, R. M., \& Isaacs, J. (2010). Telling is compelling: The impact of student reports of bullying on teacher intervention. Educational Psychology, 30 , 283-296.

Orpinas, P., Home, A. M., \& Multisite Violence Prevention Project (2004). A teacher-focused approach to prevent and reduce students' aggressive behavior: The GREAT teacher program. American Journal of Preventive Medicine, 26(1 Suppl), 29-38.

Rinehart, S. J., \& Espelage, D. L. (2016). A multilevel analysis of school climate, homophobic name-calling, and sexual harassment victimization/perpetration among middle school youth. Psychology of Violence, 6, 213-222.

Santor, D. A., Messervey, D., \& Kusumakar, V. (2000). Measuring peer pressure, popularity, and conformity in adolescent boys and girls: Predicting school performance, sexual attitudes, and substance abuse. Journal of Youth and Adolescence, 29, 163-182.

Schultes, M.-T., Stefanek, E., van de Schoot, R., Strohmeier, D., \& Spiel, C. (2014). Measuring implementation of a school-based violence prevention program: Fidelity and teachers' responsiveness as predictors of proximal outcomes. Zeitschrift f€ur Psychologie, 222, 49.

Tharp, A. T., DeGue, S., Valle, L. A., Brookmeyer, K. A., Massetti, G. M., \& Matjasko, J. L. (2013). A systematic qualitative review of risk and protective factors for sexual violence perpetration. Trauma, Violence, \& Abuse, 14, 133-167.

Thornton, T. N., Craft, C. A., Dahlberg, L. L., Lynch, B. S., \& Baer, K. (2000). Best practices of youth violence prevention: A sourcebook for community action. Atlanta, GA: CDC. Available from https://www.cdc.gov/violenceprevention/ pdf/introduction-a.pdf 
Turner, H. A., Finkelhor, D., Hamby, S. L., Shattuck, A., \& Ormrod, R. K. (2011). Specifying type and location of peer victimization in a national sample of children and youth. Journal of Youth and Adolescence, 40, 1052-1067.

U.S. Equal Employment Opportunity Commission Sexual harassment. Available from: https://www.eeoc.gov/laws/types/sexual harassment . Accessed May 2019.

Vagi, K. J., Olsen, E. O., Basile, K. C., \& Vivolo-Kantor, A. M. (2015). Teen dating violence (physical and sexual) among US high school students: Findings from the 2013 National Youth Risk Behavior Survey. Journal of the American Medical Association Pediatrics, 169, 474-482.

Whitted, K. S., \& Dupper, D. R. (2005). Best practices for preventing or reducing bullying in schools. Children \& Schools, 27, 167-175.

Wilson, E. K., Dalberth, B. T., \& Koo, H. P. (2010). “We're the heroes!”: Fathers' perspectives on their role in protecting their preteenage children from sexual risk. Perspectives on Sexual and Reproductive Health, 42, 117-124.

Yoon, J. S., \& Barton, E. (2008). The role of teachers in school violence and bullying prevention. In T. W. Miller (Ed.), School violence and primary prevention (pp. 249-275). New York: Springer.

Yoon, J. S., \& Bauman, S. (2014). Teachers: A critical but overlooked component of bullying prevention and intervention. Theory Into Practice, 53, 308-314.

Young, A. M., Grey, M., \& Boyd, C. J. (2009). Adolescents' experiences of sexual assault by peers: Prevalence and nature of victimization occurring within and outside of school. Journal of Youth and Adolescence, 38, 11. 